Photoperiodism

\title{
Melatonin as a seasonal time-cue: a commercial story
}

\section{from Gerald Lincoln}

THE physiology of many of our domesticated animals varies with the seasons in the same way as that of their wild ancestors. Sheep, goats, horses, ferrets, mink and deer are seasonal in their reproduction, while cattle show a seasonal cycle in milk yield. In most animals, appetite increases in summer, fat reserves accumulate in autumn and a period of anorexia follows in the winter. Moulting also occurs seasonally, as does the growth of horns and the replacement of antlers. These seasonal traits all have obvious survival value in the wild, but in captivity they can be constraints on management; it is, for example, difficult to induce sheep or horses to conceive during their natural non-breeding season, or to make cattle and deer put on weight in the winter. One way to avoid this problem is to house the animals indoors and expose them to patterns of artificial light. A more convenient alternative, now being discussed, is to treat the animals with melatonin.

The new approach comes from the realization that melatonin, released from the pineal gland during the hours of darkness, relays the photoperiodic timecues through which seasonal species respond to the annual cycle in daylength ${ }^{1-5}$. The period for which melatonin is at a high level in the blood appears to convey 'nightlength' and to cause specific changes in the hypothalamic control of reproduction, moulting, food intake and other seasonal characteristics. By giving animals melatonin it is possible to interfere with this subtle time-keeping mechanism. Increasing the length of time for which circulating melatonin is at a high level has been found the induce the short-daylength response normally seen in winter in all the mammalian species studied so far.

There can be important differences between species in the effect of the melatonin signal, however. Reproduction is variously affected: long exposure to melatonin stimulates gonadal activity in sheep, goats and deer, all of which breed when daylength is short; but inhibits gonadal activity in horses and many smaller species, including hamsters, ferrets, voles, weasels and hares, that breed when daylength is long. Effects on moulting and appetite are more uniform: melatonin causes growth of the winter coat and anorexia.

The addition of melatonin to the diet is now a practical method of treating farm animals. Dave Kennaway and Bob Seamark $^{6}$, working in Adelaide, have shown that giving sheep $2 \mathrm{mg}$ of melatonin absorbed onto a pelletted diet produces a physiological 'night-time' increase in the blood levels of melatonin lasting up to $8 \mathrm{~h}$, the length of the effect being a result of slow absorption from the gut. They subsequently used this technique to administer melatonin to anoestrus Merino cross-bred ewes housed in summer daylengths of $16 \mathrm{~h}$ light: $8 \mathrm{~h}$ darkness. Feed containing the melatonin was given daily $8 \mathrm{~h}$ before 'lights-off' on the ground that the increase in melatonin blood levels it produced would merge with the increase in endogenous melatonin secreted during the dark phase and expose the animal for long enough to induce a short-day response. The effect was as predicted: the high blood levels of prolactin, typical of long daylengths, decreased within 17 days, heralding an early resumption of the oestrous cycle. The effect has been confirmed by Jo Arendt ${ }^{7}$ in Gilford.

Oral administration of melatonin has also been found to be effective at inducing antler maturation and rutting behaviour in male white-tailed deer ${ }^{8}$. Melatonin can even be given in the drinking water to produce a short-day response ${ }^{9}$, or simply as a small subcutaneous implant which will release a constant level of melatonin over many weeks ${ }^{10-12}$. One limitation is that prolonged treatment with melatonin leads to refractoriness ${ }^{13}$, as occurs during prolonged exposure to short days, and only by exposing animals to long days with no melatonin can responsiveness be restored.

Two models have been proposed to account for the actions of melatonin in photoperiodic time-measurement. In one, it is the total duration of melatonin exposure each day which dictates the response, while in the other it is the timing of a daily rhythm in sensitivity to melatonin relative to the period of melatonin secretion which dictates the response. In the first model, the duration of melatonin exposure is assessed in the brain by some form of hour-glass. In the second, the critical feature is the way the daily photoperiod entrains the phase of the rhythm in brain sensitivity and the rhythm in melatonin secretion.

Supporting the first hypothesis are the results of numerous experiments in which the duration of exposure to melatonin has been increased by the addition of exogenous melatonin to induce a short-day response. Elegant studies performed by Bruce Goldman ${ }^{14.15}$ working with Djungarian hamsters and Eric Bittman ${ }^{16}$ working with Suffolk sheep, in which programmed infusions of melatonin are given for a set duration each day, have provided compelling evidence for the importance of duration. If the blood levels of melatonin are continuously elevated for more than 12 h every day for several weeks, a short-day response is seen; but if they are elevated for only short periods, even if more than once each day, then a long-day response is seen.

These experiments do not, however, totally rule out the second 'time-of-day' hypothesis. Larry Tamark ${ }^{17}$ first showed in 1976 that injecting hamsters on longdaylight regimes with melatonin caused a short-day reproductive response if the injection was given in the subjective 'afternoon' but not if given in the 'morning'. However, the treated animals had functional pineal glands and when similar experiments were performed with pinealectomized hamsters no time effect was apparent $^{18,19}$.

The debate still continues, though, for in recent experiments, Marcia WatsonWhitmyre and Milton Stetson ${ }^{20}$ show that two precisely timed injections of melatonin given to hamsters kept on different photoperiods produce different responses.

Finally, it should be noted that although the administration of melatonin is a convenient method of inducing winter changes during the summer, there is no simple way of achieving the reverse. To do this, we need a powerful antagonist to block the action of melatonin in the brain, or a compound which specifically inhibits the release of melatonin from the pineal gland. Armed with these anti-melatonin compounds it may be possible to induce an increase in appetite of farm animals in winter and to stimulate early breeding in long-day species. It might even be possible to induce race horses to foal close to 1 January: the aim of all horse breeders.

Gerald Lincoln is at the MRC Reproductive Biology Unit, Centre for Reproductive Biology, 37 Chalmers Street, Edinburgh EH3 9EW.

I. Wurtman, R.J., Axelrod, J. \& Kelly, D.E. The Pineal (Academic, New York, 1968).

2. Wurtman, R.J. \& Anton-Tay, F. Recent Prog. Horm. Res. 25, 497 (1969)

3. Turek, F.W. \& Campbell, C.S. Biol. Reprod. 20, 32 (1979).

4. Reiter, R.J. Endocr. Rev. 1, 109 (1980)

5. Herbert, J. in Biological Clocks in Seasonal Reproductive Cycles (eds Follett, B.K. \& Wright D.E.) 261 (Wright, Bristol, 1981).

6. Kennaway, D.J., Gilmore, T.A. \& Seamark, R.F. Endocrinology 110, 1766 (1982)

7. Arendi, J., Symons, A.M., Laud, C.A. \& Pryde, S. Abstr. S8 Soc. Study of Fertility Conf., Nottingham (1982)

8. Bubenik, G. J. exp. Zool. 225, 155 (1983)

9. Pevet, P \& Haldar-Misra, C. Experentia 38, 1493 (1982).

10. Turek. F.W Proc. Soc exp. Biol Med. 155, 31 (1977)

1. Allain, D., Martinet, L. \& Rougeot, J. in Photoperiodism and Reproduction in Vertebrates (eds Ortavant, R., Pellelier, J. \& Ravault, J.P.) 263, (INRA Service des Publications, France, 1981).

12. Lincoln, G.A. Abstr. 57 Soc. Study of Fertility Conf., Nottingham; unpublished observations (1982).

3. Bittman, E.L. Science 202, 648 (1978).

14. Carter, D.S. \& Goldman, B.D. Biol. Reprod. 24, 23A (1981).

15. Goldman, B.D. Soc. Study of Reprod. 26, Abstr. 22, Suppl. 1 (1982)

16. Bittman, E.L., Karsch, F.J. \& Dempsey, R.J. 64th a. Mtg Endocr. Soc. (1982).

17. Tamarkin, L. et al. Endocrinology 99, 1541 (1976).

18. Tamarkin, L. et al. Science 198, 953 (1977).

19. Goldman, B. et al. Endocrinology 104, 82 (1979).

20. Watson-Whitmyre, M. \& Stetson, M.H. Endocrinology 112,763 (1983). 